\title{
Decrease of ZEB1 expression inhibits the B16F10 cancer stem- like properties
}

\author{
Fengshu Zhao,*, Xiangfeng $\mathrm{He}^{2, *}$, Yaqing Wang, ${ }^{1, *}$, Fangfang $\mathrm{Shi}^{1}$, Di Wu ${ }^{1}$, Meng Pan ${ }^{1}$, \\ Miao Li ${ }^{1}$, Songyan $\mathrm{Wu}^{1}$, Xiaoying Wang ${ }^{1}$, Jun Dou ${ }^{1, * *}$ \\ ${ }^{1}$ Department of Pathogenic Biology and Immunology, School of Medicine, Southeast University, Nanjing, China; \\ ${ }^{2}$ Department of Medical Oncology, Affiliated Tumor Hospital of Nantong University, Nantong, China.
}

\begin{abstract}
Summary Increasing evidence supports that cancer stem cells (CSCs) are responsible for driving tumor initiation and maintenance. Zinc-finger E-box binding homeobox 1 (ZEB1) is a transcription factor for regulating tumor progression, and contributes to maintenance of CSC-like properties. The goal of the present study is to investigate the effect of decreasing ZEB1 expression on the B16F10 CSC-like properties. The recombinant shRNA targeting ZEB1 were transfected into melanoma B16F10 cells, and shZEB1-CD133 ${ }^{+} \mathrm{CD} 44^{+} \mathrm{CSCs}$ were isolated from the stable transfected cells using the magnetic-associated cell sorting method. The shZEB1$\mathrm{CD} 133^{+} \mathrm{CD}_{4}{ }^{+} \mathrm{CSC}$-like properties were systematically analyzed. The results show the B16F10 shZEB1-CD133 ${ }^{+} \mathrm{CD}^{+} 4^{+} \mathrm{CSCs}$ significantly decreased the ability of clonogenicity, cellular proliferation, migration, and invasion. Importantly, tumorigenicity and tumor lung metastasis was significantly inhibited in $\mathrm{B} 16 \mathrm{~F} 10$ shZEB1-CD133 ${ }^{+} \mathrm{CD} 44^{+}$CSCs compared with B16F10 scramble-CD133 ${ }^{+} \mathrm{CD}_{4}{ }^{+} \mathrm{CSCs}$. The decrease of ZEB1 expression markedly resulted in downregulation of vimentin and $\mathrm{N}$-cadherin expression as well as up-regulation of $\mathrm{E}$-cadherin expression in tumor tissues from the mice injected with B16F10 shZEB1-CD44 ${ }^{+} \mathrm{CD} 133^{+} \mathrm{CSCs}$. These findings contribute to understanding the maintenance of $\mathrm{B} 16 \mathrm{~F} 10 \mathrm{CD} 133^{+} \mathrm{CD} 44^{+} \mathrm{CSC}$ like properties that was closely associated with ZEB1 expression. ZEB1 may serve as a new therapeutic target for treatment of malignant melanoma.
\end{abstract}

Keywords: Melanoma, cancer stem cells, stem-like properties, RNA interference, zinc finger E-box-binding protein 1

\section{Introduction}

Human malignant melanoma is a highly aggressive and drug-resistant skin cancer that contains cancer cell subsets with self-renewing cancer stem-like cells (CSCs). Those cells are considered responsible for tumor resistance to therapies. The frequency of these cells in the tumor, however, is still a topic of debate (1-3). Although increasing study reports were published during the past decade, which have contributed to the advance of knowledge in this field, the complex biological

\footnotetext{
*These authors contributed equally to this works.

**Address correspondence to:

Dr. Jun Dou, Department of Pathogenic Biology and Immunology, School of Medicine, Southeast University, Dingjiaqiao 87\#, Nanjing 210009, Jiangsu, China.

E-mail: njdoujun@seu.edu.cn
}

properties of melanoma CSCs and how to regulate the properties are still insufficiently understood $(4,5)$.

Accumulating evidence supports the concept that the epithelial-to-mesenchymal transition (EMT) finishes the typical phenotype changes of cellular epithelial (epithelium) and interstitial (mesenchyma) state conversion in the process of epithelial originated tumor cells, including breast, prostate, ovarian, colorectal, pancreatic cancer cells, etc. (6-8). Though melanoma is not an epithelial originated tumor, it possesses epitheliallike properties through interactions between cancer cells and tumor microenvironment to bear phenotype switching (9-11). Moreover, melanoma cells are characterized by their "stem-like" properties and their more differentiated progeny, which should be eradicated to achieve a durable cure for melanoma patients (12).

Recent discoveries have shown that breast epithelial cells can gain CSC-like properties through an EMT 
program, and residual breast cancer cells following chemotherapy are enriched in EMT and CSC-like properties, which allows metastatic CSC colonization in distant organs $(13,14)$. Zinc-finger E-box binding homeobox 1 (ZEB1), a transcription factor, is essential for the physiological processes of differentiation, cell growth, and cell death $(15,16)$, and plays a key function in regulating EMT processes of melanoma cells together with miR-200c feedback loop $(5,6,17,18)$. Thus, ZEB1 function is closely associated with the melanoma CSC-like property maintenance. For this reason, we investigated whether decreasing ZEB1 expression would inhibit the B16F10 CD $133^{+} \mathrm{CD} 44^{+} \mathrm{CSC}$-like properties by altering cellular biological behavior including the tumorigenicity and metastatic potential. The data from this study showed that down-regulating ZEB1 expression

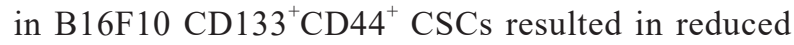
cellular self-renewing, tumorigenicity, and metastatic potential in a mouse model, suggesting that inhibition of the B16F10 CD133 ${ }^{+} \mathrm{CD} 44^{+} \mathrm{CSC}$-like properties by suppression of EMT processes in vitro and in vivo.

\section{Materials and Methods}

\subsection{Cell line and mice}

B16F10 murine melanoma cell line is syngeneic in C57BL/6 mice, ordered from the Cellular Institute of China in Shanghai. Cells were cultured at $37^{\circ} \mathrm{C}$ in $5 \%$ $\mathrm{CO}_{2}$ atmosphere in RPMI 1640 supplemented with 10\% fetal bovine serum that contained $100 \mathrm{U} / \mathrm{mL}$ penicillin $\mathrm{G}$ sodium and $100 \mathrm{mg} / \mathrm{L}$ streptomycin sulfate. C57BL/6 mice 5-6 weeks old were obtained from Yangzhou University of China. All mice were housed under pathogen-free conditions and the experiments were performed in compliance with the guidelines of the Animal Research Ethics Board of Southeast University.

\subsection{Short hairpin RNA sequence design}

Short hairpin RNA sequences of mouse ZEB1 were designed based on the ZEB1 DNA sequence (GenBank NO.NM_011546.3) using siDESIGN software (Dharmacon, http://www.thermoscientificbio.com/ design-center/) and BLAST (http://www.ncbi.nlm.nih. gov/BLAST) as well as Block-iTTM RNAi Designer (Invitrogen, Grand island, NY, USA) and were performed as described previously $(17,19)$.

\subsection{Construction of recombinant containing shRNA1 targeting the ZEB1 gene}

A pSUPER-EGFP1 (enhanced green fluorescent protein 1) vector was used to construct recombinants. The recombinant pSUPER-EGFP1-ZEB1-shRNA (shZEB1) was developed as previously described $(19,20)$. The target sequence for ZEB1 shRNA includes base pairs of
3,458-3,476 bp of the ZEB1 cDNA sequence. shRNA sequences are as follows: ZEB1-siRNA: sense, 5'-GA TCCCCAGGAAGAGGAGGAGGATAATTCAAGA GATTATCCTCCTCCTCTTCCTTTTTTGGAAA-3'; antisense, 5'-AGCTTTTCCAAAAAAGGAAGAGG AGGAGGATAATCTCTTGAATTATCCTCCTCCTC TT CCTGGG-3'; A pSUPER-EGFP1-scrambled shRNA (scramble) was used as a negative control. ScramblesiRNA: sense, 5'-GATCCCCTTCTCCGAACGTGTCA CGTTTCAAGAGAACGTGACACGTTCGGAGAATT TTTGGAAA-3'; antisense, 5'-AGCTTTCCAAAAATT CTCCGAACGTGTCACGTTCTCTTGAAACGTGAC ACGTTCGGAGAAGGG-3'. The nucleotide sequences underlined contain the restriction endonuclease Bgl II and Hind III sites, respectively. These recombinants were verified by analysis of endonuclease digestion and sequencing.

\subsection{Clonal selection, identification and isolation of CD $133^{+}$CD $44^{+}$cells}

The constructed recombinant plasmid shZEB1 were transfected into B16F10 cells by using Lipofectamine ${ }^{\mathrm{TM}}$ 2000 reagent (Invitrogen, USA) according to the manufacturer's protocol. The stably transfected clones were selected from RPMI containing $800 \mu \mathrm{g} /$ mL G418 (Clontech, CA, USA), and cloned into the cell line by limiting dilution assay. B16F10 shZEB1$\mathrm{CD} 133^{+} \mathrm{CD} 44^{+}$cells or B16F10 scramble-CD133 ${ }^{+} \mathrm{CD} 44^{+}$ cells were isolated from the B16F10-shZEB1 cells or the B16F10 scramble-cells with the magnetic activated cell sorting (MACS, Miltenyi Biotec, Gladbach, Germany) method that was performed as described previously (2,21). The isolated B16F10 shZEB1CD $133^{+} \mathrm{CD} 44^{+}$cells were named for B16F10-shZEB1 $\mathrm{CD} 133^{+} \mathrm{CD} 44^{+} \mathrm{CSCs}$ while B16F10 scrambled$\mathrm{CD} 133^{+} \mathrm{CD} 44^{+}$cells were named for B16F10Scramble-CD $133^{+}$CD $44^{+}$CSCs.

\subsection{Colony forming assay}

We investigated the colony formation capability of B16F10-shZEB1 CD $44^{+}$CD $133^{+}$CSCs. A colony with a diameter larger than $75 \mu \mathrm{m}$ or having more than 50 cells was counted as 1 positive colony according to our previous report (2). The plate clone formation efficiency was calculated as (number of colony/number of cells inoculated) $\times 100 \%$. As control, B16F10 scramble$\mathrm{CD} 133^{+} \mathrm{CD} 44^{+}$cells, and B16F10 CD $44^{+} \mathrm{CD} 133^{+} \mathrm{CSCs}$ were used in this experiment.

\subsection{Proliferative assay}

Cell proliferation was measured using a 3-(4,5-dimethylthiaxol-2-yl)-2,5- diphenyltetrazolium bromide (MTT) assay (St. Louis, Mo, CA, USA). B16F10-shZEB1 CD $133^{+} \mathrm{CD}_{4} 4^{+} \mathrm{CSCs}, \mathrm{B} 16 \mathrm{~F} 10$ 
scramble-CD $133^{+} \mathrm{CD} 44^{+}$cells, and B 16 F 10 $\mathrm{CD} 44^{+} \mathrm{CD} 133^{+} \mathrm{CSC}$ suspension were respectively seeded onto a 96 -microwell plate $\left(1 \times 10^{5} /\right.$ well $)$. The subsequent steps were performed as described in the previous report (22).

\subsection{Resistance to chemotherapeutic agents in cells}

$1 \times 10^{4} \mathrm{~B} 16 \mathrm{~F} 10$-shZEB1 CD $133^{+} \mathrm{CD} 44^{+} \mathrm{CSC}$ s or B16F10 Scramble-CD $133^{+} \mathrm{CD} 44^{+}$cells or B16F10 $\mathrm{CD} 133^{+} \mathrm{CD} 44^{+} \mathrm{CSC}$ suspensions were seeded into a 96well plate with $10 \mu \mathrm{g} / \mathrm{mL}$ epirubicin in each well for $48 \mathrm{~h}$ (Baiyunshang Company, Guangdong, China). Cellular resistance to chemotherapeutic agents was calculated according to the previous report (23).

\subsection{Cell migration assay}

To determine the role of down-regulating ZEB 1 expression on cellular migration, B16F10-shZEB1 $\mathrm{CD}_{133}{ }^{+} \mathrm{CD}_{4} 4^{+} \mathrm{CSCs}$, B16F 10 scramble-CD133 ${ }^{+} \mathrm{CD} 44^{+}$ cells, and $\mathrm{B} 16 \mathrm{~F} 10 \mathrm{CD} 133^{+} \mathrm{CD} 44^{+}$were used in the wound healing assay. Briefly, $5 \times 10^{5}$ cells per well were respectively plated in 6-well plates to form a monolayer one day before the assay; non-adherent cells were removed by PBS washing. On the following day, a uniform scratch was made down the center of the well using a sterile micropipette tip. The distance traveled by the cells was measured between the two boundaries of the cellular area at 0,12 , and $24 \mathrm{~h}$ after incubation. Each experiment was performed in triplicate $(24,25)$.

\subsection{Cell invasion assay}

Briefly, the transwell inserts with $8 \mu \mathrm{m}$ pores was coated with Matrigel (20 $\mu \mathrm{g} /$ well; Becton Dickinson, Waltham, MA, USA); the different cancer cells were seeded in the upper chamber in RPMI1640 medium supplemented with $10 \%$ fetal bovine serum. After incubation at $37^{\circ} \mathrm{C}$, the cells that invaded the lower surface of the Matrigel-coated membranes were fixed with $70 \%$ ethanol and stained with trypan blue; cells from five randomly selected fields were then counted under a light microscope $(24,25)$.

\subsection{In vivo tumorigenicity experiments}

The C57BL/6 mice (female, weight: 16-18 g and age between 5 and 6 weeks) were randomly divided into three groups of equal size (three per group): the B16F10-shZEB1 CD $133^{+} \mathrm{CD} 44^{+} \mathrm{CSC}$ group, the B16F10 scrambled-CD $133^{+} \mathrm{CD} 44^{+} \mathrm{CSC}$ group, and the B16F10 CD $133^{+} \mathrm{CD} 44^{+} \mathrm{CSC}$ group. The back of the mice were subcutaneously (s.c.) injected with $5 \times 10^{5}$ of the above cells, respectively. Except for observation of mouse general conditions each day, such as overall behavior, feeding, body weight and appearance of fur, tumor formation and growth in the groups were monitored every two days by 2 -dimensional measurements of individual tumors from each mouse. The endpoint for this study was one diameter of tumor $\geq 15 \mathrm{~mm}$, at which point mice were euthanized. The tumorigenicity experiment was repeated twice $(22,26)$.

\subsection{Tissue histopathology}

To evaluate tumor metastases to the lung, lung tissues were removed from the mice; after the metastatic tumor nodes were counted the lung tissues were fixed in $10 \%$ formalin and then embedded in paraffin. Tissue sections of $4 \mu \mathrm{m}$ thin were cut and mounted on SuperFrost Plus glass slides; the lung tissue sections were fixed in methanol and stained in hematoxylin and eosin (HE). The slides were viewed under a Zeiss Axioplan light microscope at a magnification of $\times 100$ or 400 . Arrows represent the metastatic melanoma cells $(22,27)$.

\subsection{Immunohistochemistry}

Immunohistochemistry was performed as reported previously $(27,28)$. Briefly, $4 \mu \mathrm{m}$-thin formalin fixed and paraffin-embedded tumor slides were incubated with the rabbit anti-mouse/human ZEB1, vimentin, and E-cadherin, respectively, overnight at $4{ }^{\circ} \mathrm{C}$. The antibody concentration was 1:500. The samples were then labeled with horseradish peroxidase-conjugated streptavidin (Invitrogen, CA, USA), and the chromogenic reaction was developed by using Liquid DAB Substrate Pack according to the manufacturer's instructions. The stained cells from random and non-overlapping fields were counted under a magnification of $\times 200$.

\subsection{Western blot}

Approximately $1 \times 10^{6}$ tumor tissue cells were collected and lysed in the protein extraction buffer (Novagen, Madison, WI, USA) by following the manufacturer's protocol. Protein $(15 \mu \mathrm{g} / \mathrm{lane})$ was separated by SDS/ PAGE (12\% gels) and transferred onto a nitrocellulose membrane. The membrane was blocked with saturating buffer for $1 \mathrm{~h}$ at $25^{\circ} \mathrm{C}$, followed by specific antibodies: the rabbit anti-mouse/human ZEB1, vimentin, and E-cadherin (Bioworld Technology, USA), respectively, overnight at $4^{\circ} \mathrm{C}$. The membrane was rinsed for $5 \mathrm{~min}$ with an antibody wash solution 3 times before adding to it the goat anti-rabbit fluorescence secondary antibody. Immunoreactive bands were detected by an Odyssey scanning instrument (LI-COR Odyssey Imaging System, USA). Protein semi-quantitation was calculated using Image Lab software developed by Bio-Rad $(6,28)$.

\subsection{Statistical analysis}

Values of interest were presented as the mean plus or 
minus standard deviation. Statistical comparisons were performed using the Student's $t$-test method. Bonferroni correction was used where multiple comparisons were made. A $p$ value of $<0.05$ was considered statistically significant.

\section{Results}

3.1. Decrease of ZEB1 expression in $C D 133^{+} C D 44^{+}$ CSCs reduces its ability for colony formation, proliferation, drug resistance, migration, and invasion

To understand the B16F10 CD $133^{+} \mathrm{CD} 44^{+} \mathrm{CSC}$-like properties, we first decreased cellular ZEB1 expression with the RNA interference technique, and then observed the biological behavior that exhibits stem-like properties. The results in Figures $1 \mathrm{~A}$ and $1 \mathrm{~B}$ show that B16F10 shZEB1-CD $133^{+}$CD $44^{+}$CSCs significantly decreased the colony forming rates in common plate medium compared with B16F10 CD $133^{+} \mathrm{CD} 44^{+} \mathrm{CSCs}$ (19\% vs. 53\%, $p<0.0005)$, and B16F10 scramble$\mathrm{CD} 133{ }^{+} \mathrm{CD}_{44}{ }^{+} \mathrm{CSCs}(19 \%$ vs. $48 \%, p=0.0043)$, respectively; in soft agar medium, the colony forming rates of $\mathrm{B} 16 \mathrm{~F} 10$ shZEB1-CD $133^{+} \mathrm{CD} 44^{+} \mathrm{CSCs}$ was also significantly decreased compared with $\mathrm{B} 16 \mathrm{~F} 10$ CD $133{ }^{+} \mathrm{CD}_{4}{ }^{+} \mathrm{CSCs}(8.5 \%$ vs. $41.5 \%, p<0.0001)$, and B16F10 scramble-CD133 ${ }^{+} \mathrm{CD} 44^{+} \mathrm{CSCs}(8.5 \%$ vs. $31.9 \%, p<0.0003)$, respectively. Figure $1 \mathrm{C}$ shows that the proliferative activity of B16F10 shZEB1CD $133^{+} \mathrm{CD}_{4} 4^{+} \mathrm{CSCs}$ dynamically every $24 \mathrm{~h}$ as measured by the OD value was markedly reduced when compared with B16F10 CD133 ${ }^{+} \mathrm{CD} 44^{+} \mathrm{CSCs}(p<0.01)$ or B16F10 scramble-CD133 ${ }^{+} \mathrm{CD} 44^{+} \mathrm{CSCs}(p<0.05)$. Figure 1D shows that drug resistance to epirubicin in B16F10 shZEB1-CD133 $3^{+}$D $44^{+}$CSCs was decreased, which was statistically significant compared with B16F10 CD133 ${ }^{+} \mathrm{CD}_{4} 4^{+} \mathrm{CSCs}$ (41.24\% vs. 61.46\%, $p$ $=0.0130)$ or B16F10 scramble-CD $133^{+} \mathrm{CD} 44^{+} \mathrm{CSCs}$ (41.24\% vs. 59.45\%, $p=0.0248)$.

In addition, the ability of migration and invasion in $\mathrm{B} 16 \mathrm{~F} 10 \mathrm{CD} 133^{+} \mathrm{CD} 44^{+} \mathrm{CSC}$ s with down-regulated ZEB1expression was significantly inhibited as compared to control cells. We found in Figures 2A and $2 \mathrm{~B}$ that the results at $24 \mathrm{~h}$ showed a statistically significant reduction in wound closures in $\mathrm{B} 16 \mathrm{~F} 10$ shZEB1-B16F10 CD $133^{+} \mathrm{CD} 44^{+} \mathrm{CSCs}$ compared with B16F10 CD133 ${ }^{+} \mathrm{CD} 44^{+} \mathrm{CSCs}(p=0.0033)$ or B16F10 scramble-CD133 ${ }^{+}$CD $44^{+}$CSCs $(p=0.0074)$. Consistently, the effect of down- regulated ZEB1 expression on $\mathrm{B} 16 \mathrm{~F} 10 \mathrm{CD} 133^{+} \mathrm{CD} 44^{+} \mathrm{CSC}$ invasive ability was also inhibited, which was done using the transwell invasive assay. The representative photos in Figure 2C show the cell invasive ability was statistically significantly decreased in B16F10 shZEB1-CD $133^{+} \mathrm{CD} 44^{+} \mathrm{CSC}$ compared with B16F10 $\mathrm{CD} 133^{+} \mathrm{CD} 44^{+} \mathrm{CSCs}(p<0.0001)$ or B16F10 scramble-

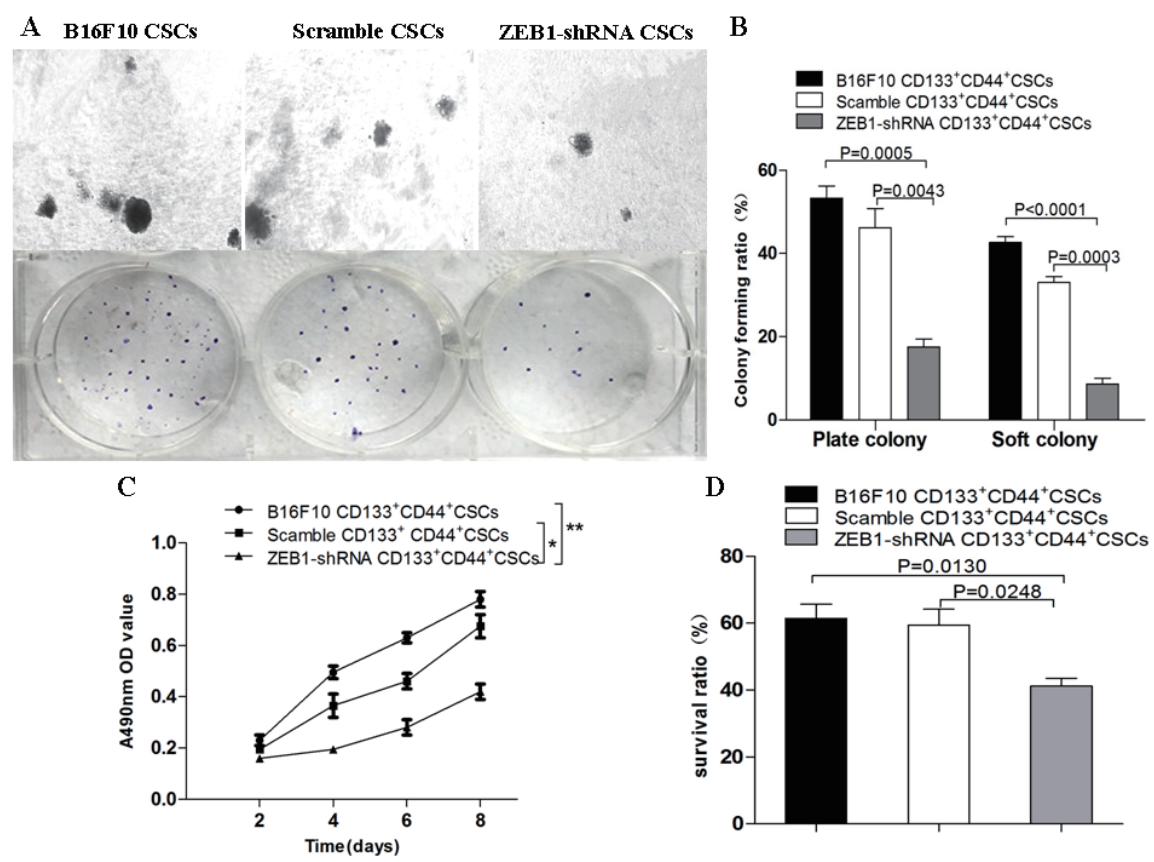

Figure 1. Short hairpin ZEB1-B16F10 CD133 ${ }^{+} \mathrm{CD} 44^{+} \mathrm{CSC}$ decreases the ability of colony forming, cell proliferation as well as drug resistance in vitro. (A) The colony forming ratios of $\mathrm{B} 16 \mathrm{~F} 10 \mathrm{ZEB} 1$-shRNA-CD $133^{+} \mathrm{CD} 44^{+} \mathrm{CSCs}$ in plate and soft agar medium was significantly decreased compared with the ratio in $\mathrm{B} 16 \mathrm{~F} 10 \mathrm{CD} 133^{+} \mathrm{CD} 44^{+} \mathrm{CSCs}$ and $\mathrm{B} 16 \mathrm{~F} 10$ scramble$\mathrm{CD} 133^{+} \mathrm{CD} 44^{+}$CSCs. (B) Between-group differences of colony-forming ratios in the plate medium and the soft agar medium; all the differences were statistically significant. (C) The cell proliferation ability in vitro was detected by MTT assay. At day 8 , the proliferation of B16F10 ZEB1- shRNA-CD $133^{+} \mathrm{CD} 44^{+}$CSCs was significantly inhibited compared with B16F10 CD133 $3^{+} \mathrm{CD} 44^{+}$ CSCs and B16F10 scramble-CD133 ${ }^{+}$CD $44^{+}$CSCs. (D) Drug resistance to epirubicin $(10 \mu \mathrm{g} / \mathrm{mL})$ in B16F10 ZEB1-shRNA$\mathrm{CD} 133^{+} \mathrm{CD} 44^{+} \mathrm{CSCs}$ was significantly reduced compared with B16F10 CD $133^{+} \mathrm{CD} 44^{+} \mathrm{CSCs}$ and B $16 \mathrm{~F} 10$ scramble$\mathrm{CD} 133^{+} \mathrm{CD} 44^{+} \mathrm{CSCs}$; refer to the statistically significant differences as indicated. 


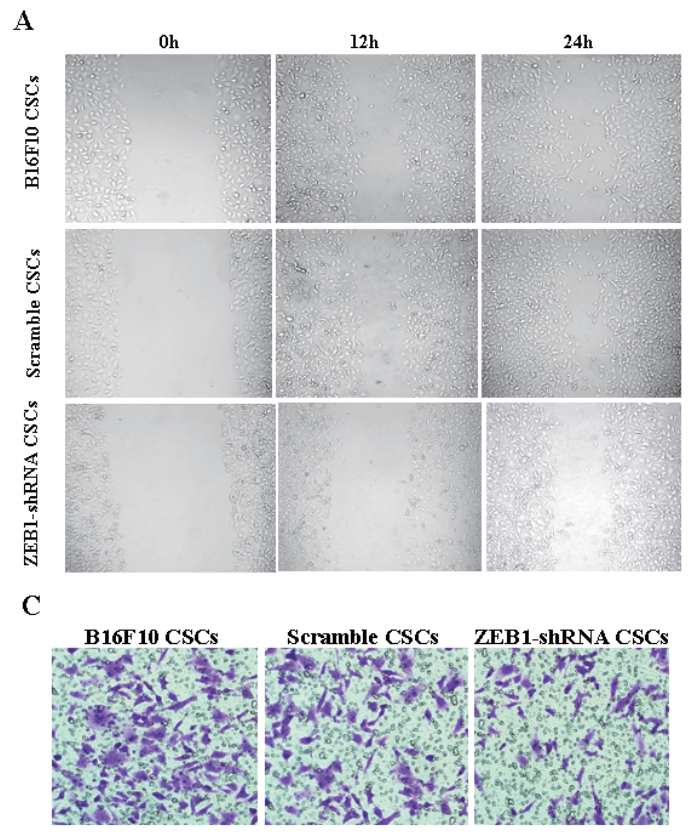

B
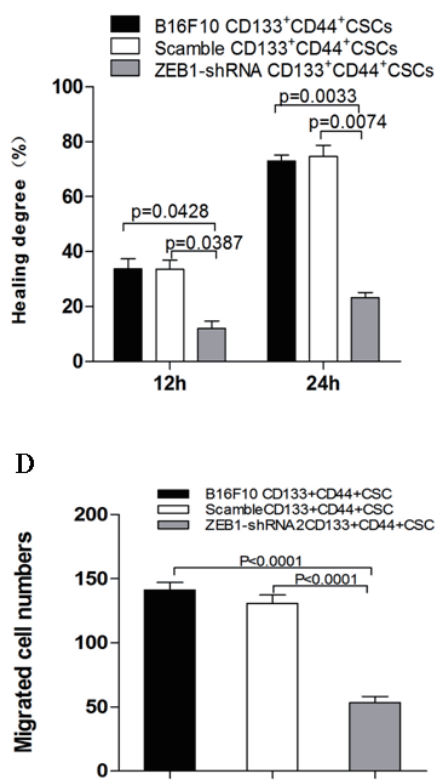

Figure 2. Short hairpin ZEB1-B16F10 CD133 ${ }^{+} \mathrm{CD}_{4}{ }^{+} \mathrm{CSCs}$ reduces the ability of migration and invasion in vitro. (A) The wound-healing assay shows that the migration ability in B16F10 ZEB1-shRNA-CD133 ${ }^{+} \mathrm{CD} 44^{+} \mathrm{CSCs}$ was decreased compared with that of B16F10 CD133 ${ }^{+} \mathrm{CD} 44^{+} \mathrm{CSCs}$ and B16F10 scramble-CD133 ${ }^{+} \mathrm{CD} 44^{+}$CSCs. (C) The invasive ability of B16F10 ZEB1-shRNA-CD $133^{+} \mathrm{CD} 44^{+} \mathrm{CSCs}$ was markedly decreased compared with that of B16F10 CD133 ${ }^{+} \mathrm{CD} 44^{+} \mathrm{CSCs}$ and $\mathrm{B} 16 \mathrm{~F} 10$ scramble-CD133 $3^{+} \mathrm{CD} 44^{+} \mathrm{CSCs}$ in the invasive assay. (B and D) Between- group differences in the healing degree, and in the invasive cells; all differences were statistically significant; refer to the statistically significant differences as indicated.

A

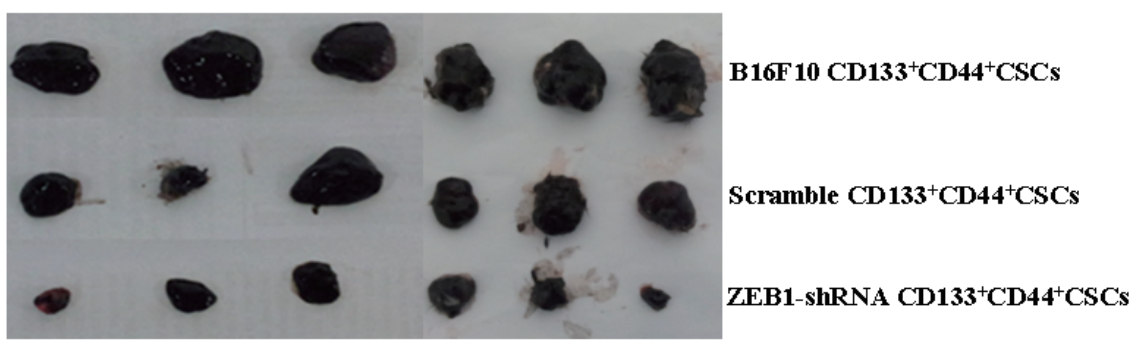

B

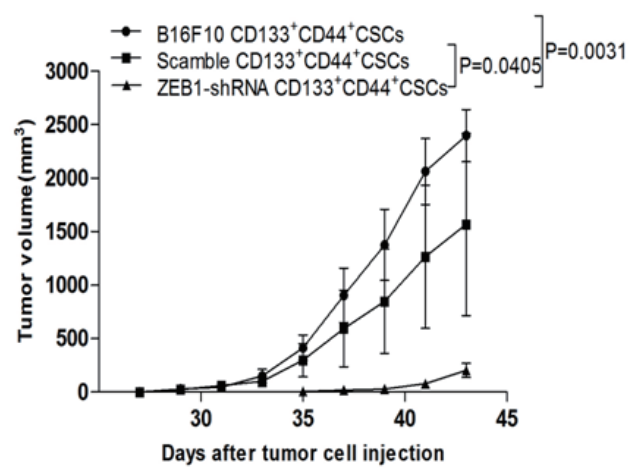

$\mathrm{C}$

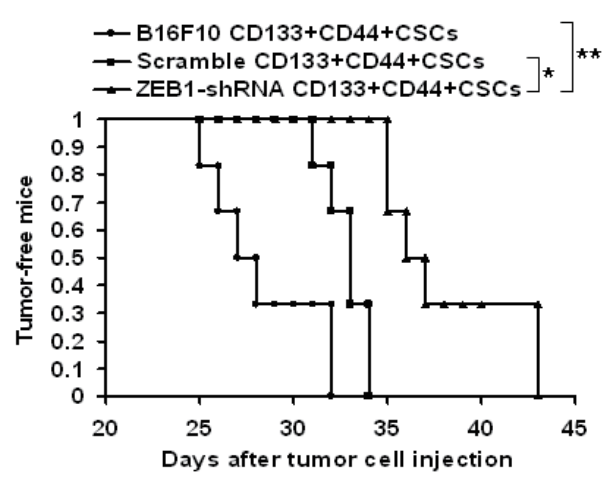

Figure 3. The knockdown of $\mathrm{ZEB} 1$ in $\mathrm{B} 16 \mathrm{~F} 10 \mathrm{CD} 133^{+} \mathrm{CD} 44^{+} \mathrm{CSC}$ inhibits the tumorigenicity and tumor progression in mice. (A) The representative images show the tumor sizes stripped from the mice 43 days after mice were injected with the 5 $\times 10^{5}$ B16F10 ZEB1-shRNA-CD $133^{+} \mathrm{CD} 44^{+} \mathrm{CSCs}, \mathrm{B} 16 \mathrm{~F} 10 \mathrm{CD} 133^{+} \mathrm{CD} 44^{+} \mathrm{CSCs}$ and B16F10 scramble-CD133 ${ }^{+} \mathrm{CD} 44^{+} \mathrm{CSCs}$, respectively. (B) Tumor growth dynamic state in mice injected with the above different cells. (C) Days of tumor-free mice injected with the above different cells.

$\mathrm{CD}_{133}{ }^{+} \mathrm{CD} 44^{+} \mathrm{CSCs}(p<0.0001)$ when these cells were cultured for $48 \mathrm{~h}$ (Figure 2D).

This findings implied that the maintenance of the $\mathrm{B} 16 \mathrm{~F} 10 \mathrm{CD} 133^{+} \mathrm{CD} 44^{+}$CSC-like properties, including self-renewal (colony forming and proliferative activity) and drug resistance as well as metastasis (the ability of migration and invasion), may mainly depend on ZEB1 expression or not. 


\subsection{Decrease of ZEB1 expression in B $16 F 10$ $C D 133^{+} \mathrm{CD}_{4} 4^{+} \mathrm{CSCs}$ inhibits tumorigenicity and metastasis in mice}

Having found the effects of down-regulated ZEB1 expression on cellular biological behaviors that exhibit the $\mathrm{B} 16 \mathrm{~F} 10 \mathrm{CD} 133^{+} \mathrm{CD} 44^{+} \mathrm{CSC}$-like properties in vitro, we wanted to know if these effects would inhibit tumorigenicity and metastatic potential of B16F 10 shZEB1-CD $133^{+} \mathrm{CD} 44^{+} \mathrm{CSC}$ s in the mouse model. Images in Figure 3A indicate that the tumor sizes on day 43 after the mice were injected with B16F10 cells. We found that all 6 mice developed tumors in 35 days after being injected with $5 \times 10^{5}$ B16F10 shZEB1$\mathrm{CD} 133^{+} \mathrm{CD} 44^{+} \mathrm{CSCs}$, however, the tumor volume, the time of tumor occurrence, and the tumor-free mice days were significantly different from the other mice, which was statistically significant compared with the B16F10-scramble-CD133 $3^{+} \mathrm{CD} 44^{+} \mathrm{CSCs}$ group $(p<$ $0.05)$ and the $\mathrm{B} 16 \mathrm{~F} 10-\mathrm{CD} 133^{+} \mathrm{CD} 44^{+} \mathrm{CSC}$ group $(p$ $<0.01$ ), respectively. Figure 3B presents the dynamic state changes of tumor volumes in B16F10 melanoma bearing mice, while Figure $3 \mathrm{C}$ exhibits the B16F10 melanoma bearing mouse survival days in the three groups were obviously different from each other. These differences were statistically significant in shZEB1$\mathrm{CD} 133^{+} \mathrm{CD} 44^{+} \mathrm{CSCs}$ in contrast with $\mathrm{B} 16 \mathrm{~F} 10$ scramble-CD $133^{+} \mathrm{CD} 44^{+} \mathrm{CSCs}(p<0.05)$, and B16F10scramble-CD $133^{+} \mathrm{CD} 44^{+} \mathrm{CSCs}(p<0.05)$, respectively.

Consistently, the down-regulation of ZEB 1 expression in $\mathrm{B} 16 \mathrm{~F} 10-\mathrm{CD} 133^{+} \mathrm{CD} 44^{+} \mathrm{CSC}$ markedly reduced tumor lung metastasis. This efficacy was assessed by observation of lung tumor nodes 43 days after mice were injected with the various cells (Figure 4A). Representative images of lung tissues show tumor nodes in the different mice, which was statistically significant between the B16F10 shZEB1-CD133 ${ }^{+} \mathrm{CD} 44^{+}$ $\mathrm{CSC}$ group and the $\mathrm{B} 16 \mathrm{~F} 10 \mathrm{CD} 133^{+} \mathrm{CD} 44^{+} \mathrm{CSC}$ group $(p=0.007)$, or between the $\mathrm{B} 16 \mathrm{~F} 10$ shZEB1$\mathrm{CD} 133^{+} \mathrm{CD} 44^{+} \mathrm{CSC}$ group and the $\mathrm{B} 16 \mathrm{~F} 10$ scramble$\mathrm{CD} 133^{+} \mathrm{CD} 44^{+} \mathrm{CSC}$ group $(p=0.0232)$ (Figure 4B). Notably, a few metastatic tumor cells were seen in lung tissue sections from the mice injected with the B16F10 shZEB1-CD $133^{+} \mathrm{CD} 44^{+} \mathrm{CSC}$ as analyzed by $\mathrm{HE}$ staining (Figure 4C). However, a lot of metastatic tumor cells were found in the lung tissue sections from the mice injected with the $\mathrm{B} 16 \mathrm{~F} 10 \mathrm{CD} 133^{+} \mathrm{CD} 44^{+} \mathrm{CSC}$ or $\mathrm{B} 16 \mathrm{~F} 10$ scramble-CD133 ${ }^{+} \mathrm{CD} 44^{+} \mathrm{CSCs}$ as are shown in
A

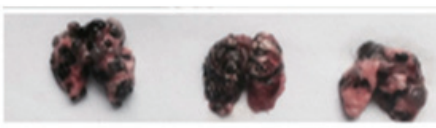

B16F10 $\mathrm{CD} 33^{+} \mathrm{CD}^{+} 4^{+} \mathrm{CSCs}$

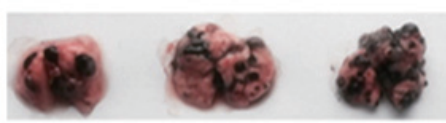

Scramble $\mathrm{CD} 133^{+} \mathrm{CD} 44^{+} \mathrm{CSCs}$

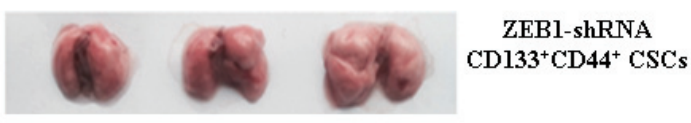

B16F10 CD133 ${ }^{+} \mathrm{CD} 44^{+} \mathrm{CSCs}$
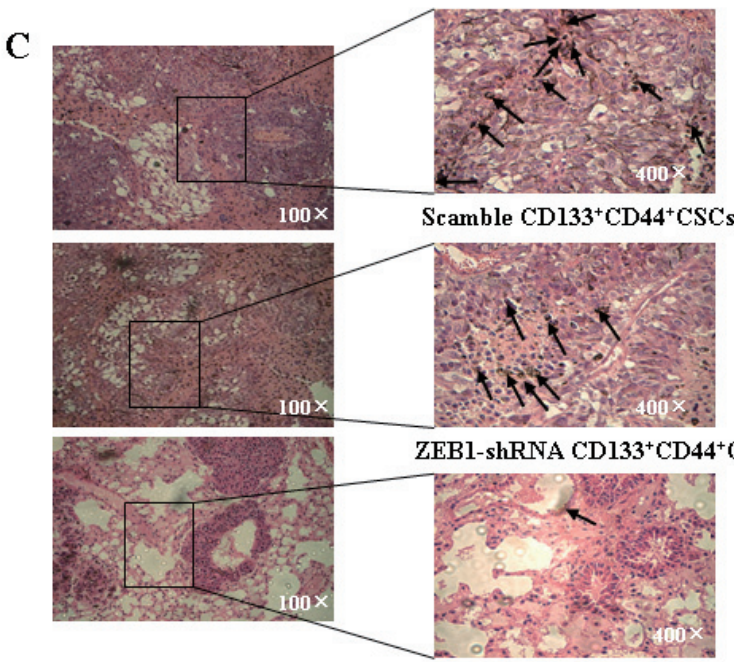

B

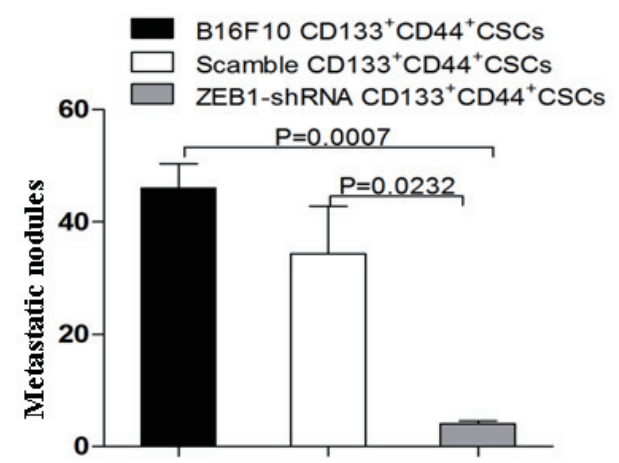

D

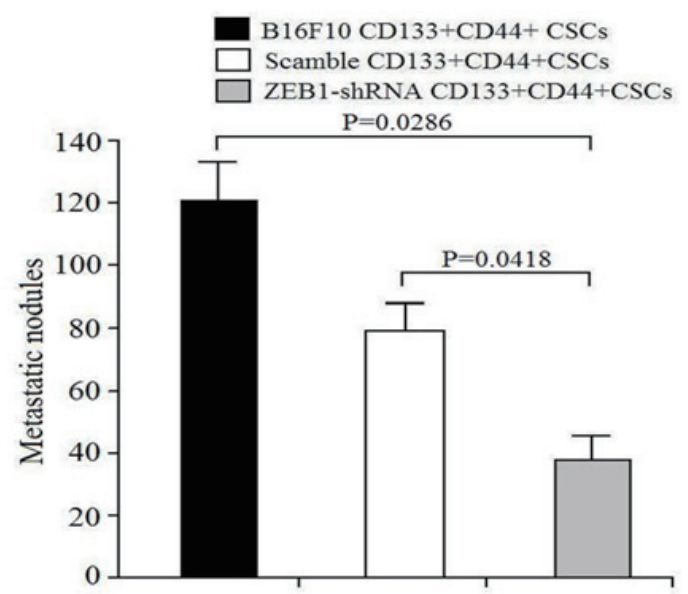

Figure 4. The knockdown of $\mathrm{ZEB} 1$ in $\mathrm{B} 16 \mathrm{~F} 10 \mathrm{CD} 33^{+} \mathrm{CD}_{4}{ }^{+} \mathrm{CSC}$ inhibits tumor lung metastasis in mice. (A) Images show tumor metastatic nodes in mouse lungs stripped from the mice 43 days after mice were injected with $5 \times 10^{5} \mathrm{~B} 16 \mathrm{~F} 10$ ZEB1-shRNA-CD133 ${ }^{+} \mathrm{CD} 44^{+} \mathrm{CSCs}, \mathrm{B} 16 \mathrm{~F} 10 \mathrm{CD} 133^{+} \mathrm{CD} 44^{+} \mathrm{CSCs}$ and B16F10 scramble-CD133 ${ }^{+} \mathrm{CD} 44^{+} \mathrm{CSCs}$, respectively. (B) Quantification analysis of lung tumor metastatic node counts. (C) Tissue sections derived from the mice 43 days after mice were injected with the above different cells, respectively. Arrows point to the metastatic focus $(400 \times)$. (D) Between-group differences in the tumor metastatic focus in the different lung sections; refer to the statistically significant differences as indicated. 
Figures 4C and 4D. From these results, we concluded that the B16F10 CD $133^{+} \mathrm{CD} 44^{+} \mathrm{CSC}$-like properties were significantly inhibited in the in vivo mouse model.

\subsection{Impacts of down-regulation of ZEB1 in B16F10} CD $133^{+} \mathrm{CD}_{4} 4^{+} \mathrm{CSCS}$ on EMT-related molecular expression in tumor tissues

To evaluate the functional significance of the decrease of ZEB1 expression, we tested the expression of ZEB1, E-cadherin, N-cadherin, and vimentin in the tumor tissues from B16F10 melanoma bearing mice
A

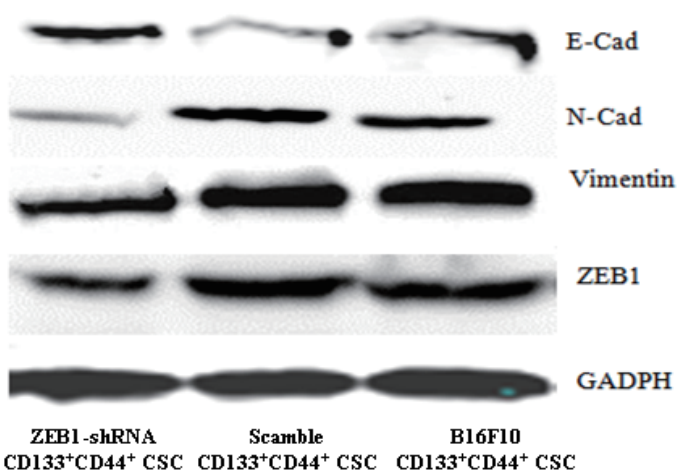

B

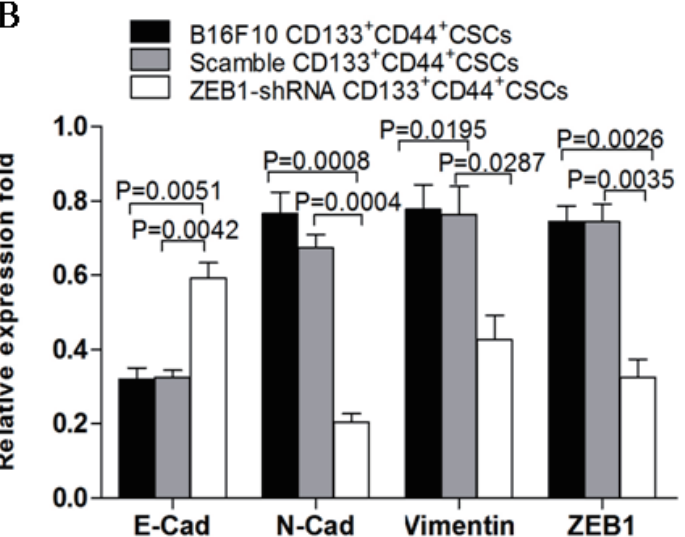

Figure 5. Detection of tumor EMT markers by Western blot. (A) The expression of E-cadherin, N-cadherin, vimentin, and ZEB1 in tumor tissues from mice injected with $5 \times 10^{5}$ B16F10 ZEB1-shRNA-CD133 ${ }^{+} \mathrm{CD}_{4} 4^{+} \mathrm{CSCs}$, B16F10 CD133 $3^{+} \mathrm{CD} 44^{+}$ CSCs and B16F10 Scramble-CD $133^{+} \mathrm{CD} 44^{+} \mathrm{CSCs}$, respectively. (B) Quantification analysis of molecular expression; refer to the statistically significant differences as indicated.

A

B16F10 CD133' ${ }^{+} \mathrm{CD} 44^{+}$
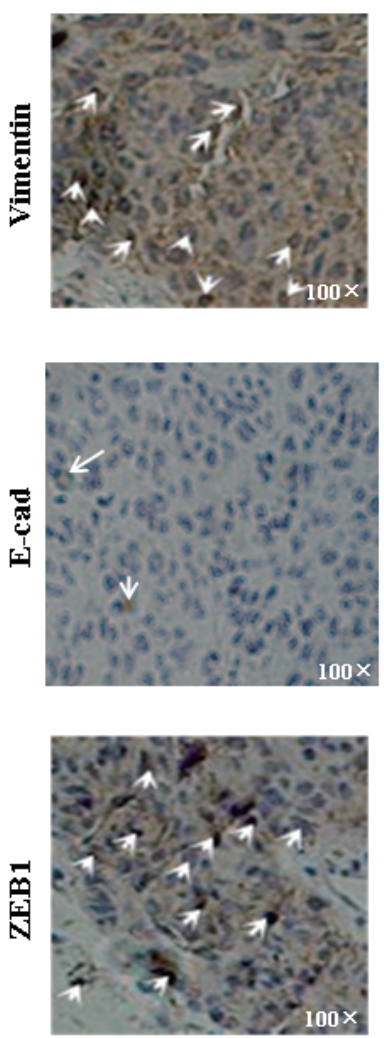

Scramble CD133+ ${ }^{+} D 44^{+}$
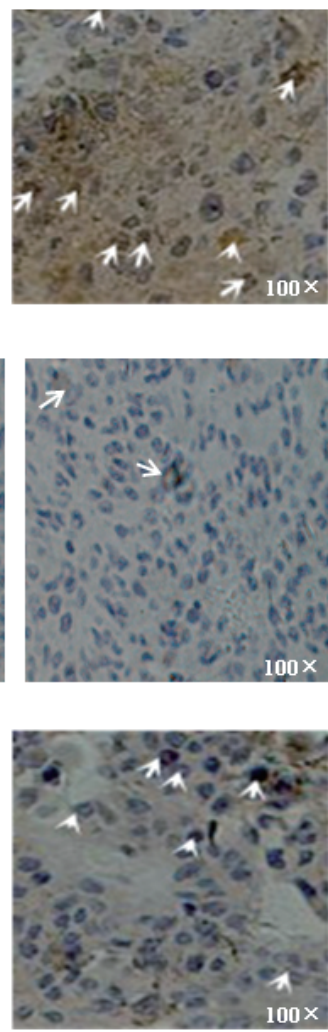
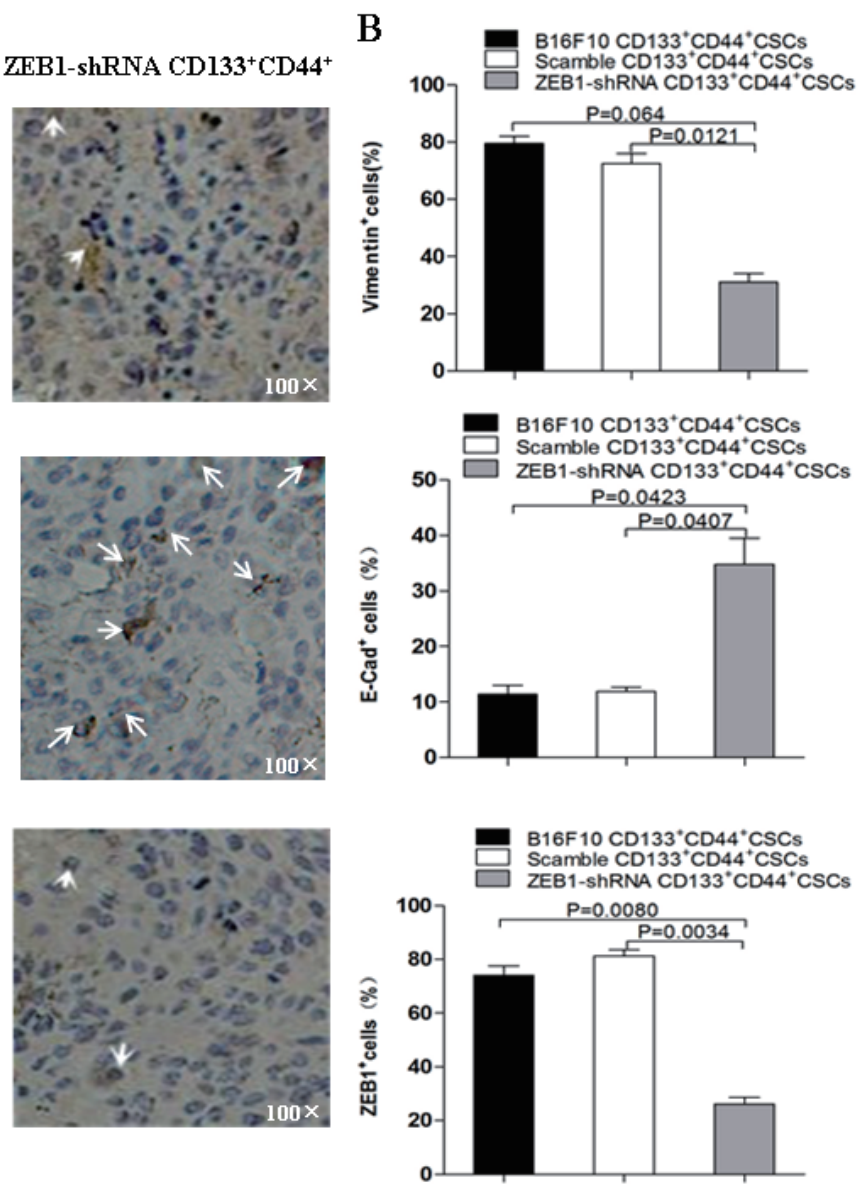

Figure 6. Detection of tumor EMT markers by immunohistochemistry. (A) The expression of vimentin, E-cadherin, and ZEB1 in tumor tissues from mice injected with $5 \times 10^{5}$ B16F10 ZEB1-shRNA-CD133 ${ }^{+}$CD $44^{+}$CSCs, B16F10 CD133 ${ }^{+}$CD44 CSCs and B16F10 scramble-CD133 ${ }^{+} \mathrm{CD} 44^{+} \mathrm{CSCs}$, respectively. Arrows point to positive cells that expressed the EMT associated molecules $(100 \times)$. (B) The semi-quantification analysis of molecular expression; refer to the statistical differences as indicated. 
by Western blot analysis. Figure 5A shows E-cadherin expression in the B16F10 shZEB1-CD $133^{+} \mathrm{CD} 44^{+}$ CSCs was markedly higher than that of both B16F10 $\mathrm{CD} 133^{+} \mathrm{CD} 44^{+} \mathrm{CSCs}$ and B $16 \mathrm{~F} 10$ scramble$\mathrm{CD} 133^{+} \mathrm{CD} 44^{+} \mathrm{CSCs}$. There were significant differences between the B16F10 shZEB1-CD133 ${ }^{+} \mathrm{CD} 44^{+} \mathrm{CSCs}$ and the $\mathrm{B} 16 \mathrm{~F} 10 \mathrm{CD} 133^{+} \mathrm{CD} 44^{+} \mathrm{CSCs}(p=0.0051)$, and between the B16F10 shZEB1-CD133 ${ }^{+} \mathrm{CD} 44^{+}$ CSCs and the B16F10 scramble-CD $133^{+} \mathrm{CD} 44^{+} \mathrm{CSCs}$ $(p=0.0042)$. Whereas the ZEB1, N-cadherin, and vimentin indicated much lower expression in the B16F10 shZEB1-CD133 ${ }^{+} \mathrm{CD} 44^{+} \mathrm{CSCs}$ than either

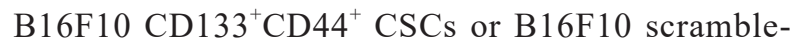
CD $133^{+} \mathrm{CD} 44^{+} \mathrm{CSCs}$, which was statistically significant as is shown in Figure 5B.

Similarly, the results of the immu $\neg$ nohistochemistry in panels $\mathrm{A}$ and $\mathrm{C}$ of Figure 6 show the E-cadherin expression in B16F10 shZEB1-CD $133^{+} \mathrm{CD} 44^{+} \mathrm{CSCs}$ was significantly increased while expression of vimentin and ZEB-1 was decreased compared with B16F10 CD133 ${ }^{+} \mathrm{CD} 44^{+} \mathrm{CSCs}$ and B16F10 scramble$\mathrm{CD} 133^{+} \mathrm{CD} 44^{+} \mathrm{CSCs}$, which was statistically significant as is shown in Figure 6B. These results demonstrated that the increased expression of E-cadherin coupled with the decreased expression of vimentin and ZEB1 may have inhibited the EMT process of B16F10 shZEB1-CD $133^{+} \mathrm{CD} 44^{+}$CSCs in the mouse model.

\section{Discussion}

It is known that there are a subset of cells within a tumor with "stem-like" properties. These cells represent a distinct tumor subpopulation known as CSCs that are responsible for tumor initiation, progression, metastasis, therapeutic resistance and relapse (29). In this study, we focused on the melanoma B16F10 CD133 ${ }^{+} \mathrm{CD} 44^{+}$ CSC-like properties, and wanted to know whether the inhibition of the B16F10 CSC-like properties would alter cellular tumorigenicity and metastasis potential. We selected the transcription factor ZEB1 as a target to inhibit the B16F10 CSC-like properties because this is the role of ZEB1 and is tightly related with the melanoma' CSC-like properties as described by previous reports $(5,6,17,18,30)$.

Since self-renewal is one of the main B16F10 CSClike properties, we first assessed the clone formation capability and proliferative activity of B16F10 shZEB1-

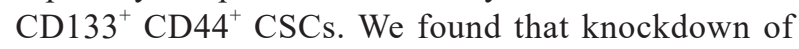
ZEB1 not only markedly decreased clone formation capability in common plate and soft agar media, and proliferative activity of $\mathrm{B} 16 \mathrm{~F} 10 \mathrm{CD} 133^{+} \mathrm{CD} 44^{+} \mathrm{CSCs}$, but also significantly reduced the drug resistance to epirubicin as well as the ability of migration and invasion in vitro compared to $\mathrm{B} 16 \mathrm{~F} 10 \mathrm{CD} 133^{+} \mathrm{CD} 44^{+}$ CSCs and scramble-CD $133^{+} \mathrm{CD} 44^{+} \mathrm{CSCs}$. The data from this study demonstrated that the knockdown of ZEB1 in B16F10 CD133 ${ }^{+} \mathrm{CD} 44^{+} \mathrm{CSC}$ reduced the ability for self-renewal, migration and invasion, which may represent the decrease of tumor cell invasiveness and stem-like properties, suggesting inhibitory roles on $\mathrm{B} 16 \mathrm{~F} 10 \mathrm{CD} 133^{+} \mathrm{CD} 44^{+} \mathrm{CSC}-$ like properties. More importantly, the knockdown of ZEB1 in B16F10 $\mathrm{CD} 133^{+} \mathrm{CD} 44^{+} \mathrm{CSCs}$ inhibited the tumorigenicity and distant lung metastasis potential. According to the CSC hypothesis, the tumorigenicity and metastasis potential represent mainly CSC-like properties in epithelial originated tumor cells $(31,32)$. Consistent with the previously reported findings $(2,5,6,17)$, our current study demonstrated that B16F10 CD $133^{+} \mathrm{CD} 44^{+} \mathrm{CSCs}$ had a multipotent, self-renewal capacity and strong tumorigenesis, while the decrease of ZEB1 expression in $\mathrm{B} 16 \mathrm{~F} 10 \mathrm{CD} 133^{+} \mathrm{CD} 44^{+} \mathrm{CSCs}$ caused reduction of CSC-like properties, which may be good evidence that ZEB1 serves as a crucial factor to maintain CSC-like properties.

Metastasis is associated with poor prognosis for melanoma, which is responsible for about $90 \%$ of skin cancer-related mortality. The capacity of cancer cells to undergo EMT is now considered a hallmark of tumor metastasis $(11,31)$. For this purpose, we tested EMT related molecular expression in the tumor tissues. Apparently, B16F10 shZEB1-CD $133^{+} \mathrm{CD} 44^{+} \mathrm{CSCs}$ exhibited significantly decreased ZEB1 expression compared with the control cells in the tumor tissues analyzed by Western blot and immu $\neg$ nohistochemistry assays. In addition, the expression of E-cadherin and vimentin, which are characteristic molecules of EMT that are closely associated with typical phenotype changes of EMT in tumor cell growth and metastasis $(15,33,34)$, was significantly inhibited in the tumor tissues from the mice injected with B16F10 shZEB1CD $133^{+} \mathrm{CD}_{4} 4^{+} \mathrm{CSCs}$. These positive consistent data allow us to suppose that the reduction of tumor cell lung metastasis mainly is due to inhibition of the EMT processes of B16F10 shZEB1-CD133 ${ }^{+} \mathrm{CD} 44^{+}$CSCs.

In conclusion, the present study provides a better understanding of ZEB1 roles in melanoma B16F10 CD $133{ }^{+} \mathrm{CD} 44^{+} \mathrm{CSCs}$. These data demonstrate that the decrease of ZEB1 expression resulted in inhibitory effects on the B16F10 CD $133^{+} \mathrm{CD} 44^{+} \mathrm{CSC}$ like properties, and reduced the tumorigenesis and metastatic potential in the melanoma mouse model. These findings support the use of knockdown of ZEB1 approaches in future melanoma clinical trials.

\section{Acknowledgements}

This work was partly supported by the National Natural Science Foundation of China (No. 81202372, 81572887) and supported by the Fundamental Research Funds for the Central Universities, Southeast University (3224005409), and Graduate Research and Innovation Projects in Jiangsu Province of China (KYLX15_0185), and Jiangsu Planned Projects for Postdoctoral Research 
Funds (1301099C) as well as China Postdoctoral Science Foundation (2013M530227).

\section{References}

1. Chin L, Garraway LA, Fisher DE. Malignant melanoma: Genetics and therapeutics in the genomic era. Genes Dev. 2006; 20:2149-2182.

2. Dou J, Pan M, Wen P, Li Y, Tang Q, Chu L, Zhao F, Jiang $\mathrm{C}, \mathrm{Hu} \mathrm{W}, \mathrm{Hu} \mathrm{K}, \mathrm{Gu}$ N. Isolation and identification of cancer stem-like cells from murine melanoma cell lines. Cell Mol Immunol. 2007; 4:467-472.

3. Sztiller-Sikorska M, Koprowska K, Jakubowska J, Jakubowska J, Zalesna I, Stasiak M, Duechler M, Czyz ME. Sphere formation and self-renewal capacity of melanoma cells is affected by the microenvironment. Melanoma Res. 2012; 22:215-224.

4. Schatton T, Murphy GF, Frank NY, Yamaura K, WaagaGasser AM, Gasser M, Zhan Q, Jordan S, Duncan LM, Weishaupt C, Fuhlbrigge RC, Kupper TS, Sayegh MH, Frank MH. Identification of cells initiating human melanomas. Nature. 2008; 451:345-349.

5. Dou J, Gu N. Emerging strategies for the identification and targeting of cancer stem cells. Tumour Biol. 2010; 31:243-253.

6. He X, Wang J, Zhao F, Yu F, Chen D, Cai K, Yang C, Chen J, Dou J. Antitumor efficacy of viable tumor vaccine modified by heterogenetic ESAT- 6 antigen and cytokine IL-21 in melanomatous mouse. Immunol Res. 2012; 52:240-249.

7. Jukic DM, Rao UN, Kelly L, Skaf JS, Drogowski LM, Kirkwood JM, Panelli MC. Microrna profiling analysis of differences between the melanoma of young adults and older adults. J Transl Med. 2010; 8:27.

8. Kreiseder B, Orel L, Bujnow C, Buschek S, Pflueger M, Schuett W, Hundsberger H, de Martin R, Wiesner C. $\alpha$-Catulin downregulates E-cadherin and promotes melanoma progression and invasion. Int J Cancer. 2013; 132:521-530.

9. Rangel MC, Karasawa H, Castro NP, Nagaoka T, Salomon DS, Bianco C. Role of Cripto-1 during epithelial-to- mesenchymal transition in development and cancer. Am J Pathol. 2012; 180:2188-2200.

10. Kemper K, de Goeje PL, Peeper DS, van Amerongen R. Phenotype switching: Tumor cell plasticity as a resistance mechanism and target for therapy. Cancer Res. 2014; 74:5937-5941.

11. Laurenzana A, Biagioni A, Bianchini F, Peppicelli S, Chillà $\mathrm{A}$, Margheri $\mathrm{F}$, Luciani $\mathrm{C}$, Pimpinelli N, Del Rosso M, Calorini L, Fibbi G. Inhibition Of UPAR-TGF $\beta$ crosstalk blocks MSC-dependent EMT in melanoma cells. J Mol Med (Berl). 2015; 93:783-794.

12. Sztiller-Sikorska M, Koprowska K, Majchrzak K, Hartman M, Czyz M. Natural compounds' activity against cancer stem-like or fast-cycling melanoma cells. PLoS One. 2014; 9:e90783.

13. Scheel C, Weinberg RA. Cancer stem cells and epithelialmesenchymal transition: Concepts and molecular links. Semin Cancer Biol. 2012; 22:396-403.

14. Zhang H, Cai K, Wang J, Wang X, Cheng K, Shi F, Jiang L, Zhang Y, Dou J. MiR-7, inhibited indirectly by lincRNA HOTAIR, directly inhibits SETDB 1 and reverses the EMT of breast cancer stem cells by downregulating the STAT3 pathway. Stem Cells. 2014;
32:2858-2868.

15. Ulrike B, Schubert J, Wellner U, Schmalhofer O, Vincan E, Spaderna S, Brabletz T. A reciprocal repression between ZEB1 and members of the miR-200 family promotes EMT and invasion in cancer cells. EMBO Rep. 2008; 9:582-589.

16. Thiery JP, Acloque H, Huang RY, Nieto MA. Epithelialmesenchymal transitions in development and disease. Cell. 2009; 139:871-890.

17. Dou J, He X, Liu Y, Wang Y, Zhao F, Wang X, Chen D, Shi F, Wang J. Effect of downregulation of ZEB1 on vimentin expression, tumour migration and tumourigenicity of melanoma B16F10 cells and CSCs. Cell Biol Int. 2014; 38:452-461.

18. Kreiseder B, Orel L, Bujnow C, Buschek S, Pflueger M, Schuett W, Hundsberger H, de Martin R, Wiesner C. $\alpha$-Catulin downregulates E-cadherin and promotes melanoma progression and invasion. Int J Cancer. 2013; 13:521-530.

19. Chen D, Wang J, Zhang Y, Chen J, Yang C, Cao W, Zhang H, Liu Y, Dou J. Effect of down-regulated transcriptional repressor ZEB1 on the epithelialmesenchymal transition of ovarian cancer cells. Int J Gynecol Cancer. 2013; 23:1357-1366.

20. Dou J, Jiang C, Wang J, Zhang X, Zhao F, Hu W, He X, Li X, Zou D, Gu N. Using ABCG2-molecule-expressing side population cells to identify cancer stem-like cells in a human ovarian cell line. Cell Biol Int. 2011; 35:227234.

21. Chen J, Wang J, Zhang Y, Chen D, Yang C, Kai C, Wang $\mathrm{X}$, Shi F, Dou J. Observation of ovarian cancer stem cell behavior and investigation of potential mechanisms of drug resistance in three-dimensional cell culture. J Biosci Bioeng. 2014; 118:214-222.

22. Dou J, Wen P, Hu W, Li Y, Wu Y, Liu C, Zhao F, Hu K, Wang J, Jiang C, He X, Gu N. Identifying tumor stemlike cells in mouse melanoma cell lines by analyzing the characteristics of side population cells. Cell Biol Int. 2009; 33:807-815.

23. Mosmann TR. Colorimetric assay for cellular growth and survival: Application to proliferation and cytotoxicity assays. J Immunol Methods. 1983; 65:55-63.

24. Shen B, Chu E S, Zhao G, Man K, Wu CW, Cheng JT, Li G, Nie Y, Lo CM, Teoh N, Farrell GC, Sung JJ, Yu J. PPAR gamma inhibits hepatocellular carcinoma metastases in vitro and in mice. Br J Cancer. 2012; 106:1486-1494

25. Ngora H, Galli UM, Miyazaki K, Zöller M. Membranebound and exosomal metastasis-associated C4.4A promotes migration by associating with the $\alpha_{6} \beta_{4}$ integrin and MT1-MMP. Neoplasia. 2012; 14:95-107.

26. Mikesh LM, Kumar M, Erdag G. Evaluation of molecular markers of mesenchymal phenotype in melanoma. Melanoma Res. 2010; 20:485-495.

27. Hu WH, Wang J, Dou J, He X, Zhao F, Jiang C, Yu F, Hu $\mathrm{K}, \mathrm{Chu} \mathrm{L}, \mathrm{Li} \mathrm{X}, \mathrm{Gu} \mathrm{N}$. Augmenting therapy of ovarian cancer efficacy by secreting IL-21 human umbilical cord blood stem cells in nude mice. Cell Transplatation. 2011; 20:669-680

28. Yang X, Lin X, Zhong X, Kaur S, Li N, Liang S, Lassus H, Wang L, Katsaros D, Montone K, Zhao X, Zhang Y, Bützow R, Coukos G, Zhang L. Double-negative feedback loop between reprogramming factor LIN28 and microRNA let-7 regulates aldehyde dehydrogenase 1-positive cancer stem cells. Cancer Res. 2010; 70:9463- 
9472.

29. Yu Y, Ramena G, Elble RC. The role of cancer stem cells in relapse of solid tumors. Front Biosci (Elite Ed). 2012; 4:1528-1541.

30. Liu SJ, Tetzlaff MT, Liu A, Liegl-Atzwanger B, Guo J, $\mathrm{Xu} \mathrm{X}$. Loss of microRNA-205 expression is associated with melanoma progression. Lab Invest. 2012; 92:10841096.

31. Zimmerer RM, Korn P, Demougin P, Kampmann A, Kokemüller H, Eckardt AM, Gellrich NC, Tavassol F. Functional features of cancer stem cells in melanoma cell lines. Cancer Cell Int. 2013; 13:78.

32. Patrawala L, Calhoun T, Schneider-Broussard R, Zhou J, Claypool K, Tang DG. Side population is enriched in tumorigenic, stem-like cancer cells, whereas ABCG2+ and ABCG2- cancer cells are similarly tumorigenic. Cancer Res. 2005; 65:6207-6219.

33. Wang X, Zhao F, He X, Wang J, Zhang Y, Zhang H, Ni Y, Sun J, Wang X, Dou J. Combining TGF- $\beta 1$ knockdown and miR200c administration to optimize antitumor efficacy of B16F10/GPI-IL-21 vaccine. Oncotarget. 2015; 6:12493-12504.

Alexaki VI, Javelaud D, Van Kempen LC, et al. GLI2Mediated Melanoma Invasion and Metastasis. J Natl Cancer Inst. 2010; 102:1148-1159.

(Received August 6, 2015; Revised September 24, 2015; Accepted October 10, 2015) 